\title{
Analysis of differentially expressed genes in cold-exposed mice to investigate the potential causes of cold-induced hypertension
}

\author{
BUXIONG TUO, CHAOMIN LI, LIJING PENG, MINGXIA YE, WEI LIU, XIAOLAN ZHONG and HUI LI \\ Department of Cardiology, 451 Hospital of PLA, Xi'an, Shaanxi 710054, P.R. China
}

Received November 21, 2013; Accepted April 15, 2014

DOI: $10.3892 /$ etm.2014.1703

\begin{abstract}
Cold exposure is considered to be an important contributing factor to the high morbidity of hypertension. In order to elucidate the cause and mechanism of cold-induced hypertension $(\mathrm{CIH})$, gene expression analysis was performed on microarray data for two groups of cold-exposed mice $\left(4^{\circ} \mathrm{C}\right.$ for 1 week and $4^{\circ} \mathrm{C}$ for 5 weeks, three replicates per group) and their respective control groups maintained at $30^{\circ} \mathrm{C}$. Analysis results indicated that the differentially expressed genes with the most significance were associated with adaptive thermogenesis, fatty acid metabolism and energy metabolism. The expected marked increase in metabolism during cold exposure caused tissue hypoxia. Genes involved in the hypoxia-inducible factor signaling pathway were activated. In addition, genes associated with oxidative stress were significantly upregulated, including superoxide dismutase 2 (SOD2) and epoxide hydrolase 2 (EPHX2). The majority of genes involved in inflammation-associated pathways were shown to be downregulated in the $4^{\circ} \mathrm{C} 5$-week group. Therefore, the results of the present study indicate that tissue hypoxia and increased oxidative stress may play important roles in the process of $\mathrm{CIH}$.
\end{abstract}

\section{Introduction}

Hypertension has an increased prevalence in cold regions or during winter. Cold winters increase the severity of hypertension and trigger myocardial infarction and stroke in hypertensive patients, leading to high mortality and morbidity rates from cardiovascular complications (1-6). Therefore, it is important to further investigate the mechanisms underlying cold-induced hypertension (CIH). Previous studies that have focused on clinical epidemiology in humans have indicated that cold exposure is a risk factor of hypertension (6-8). However, the cause of $\mathrm{CIH}$ remains unknown. The thermo-

Correspondence to: Dr Hui Li, Department of Cardiology, 451 Hospital of PLA, 269 Youyidong Road, Xi'an, Shaanxi 710054, P.R. China

E-mail: swattl@126.com

Key words: cold exposure, hypoxia, oxidative stress, hypertension, gene expression, protein-protein interaction network regulatory-vascular remodeling hypothesis indicates that avoiding the ingestion of sodium chloride is key to preventing hypertension (9). By contrast, advances in mechanistic studies of $\mathrm{CIH}$ in animals indicate that the activated sympathetic nervous system $(10,11)$ initiates $\mathrm{CIH}$ via the renin-angiotensin system $(12,13)$. Additional studies have also revealed that cold exposure suppresses the expression of endothelial nitric oxide synthase and thus the formation of nitric oxide (14), as well as increasing the production of endothelin-1 (15). The hypothesis that hypertension is caused by increased oxidative stress remains controversial (16-20).

In the present study, gene expression data from cold-exposed mice, generated by an Affymetrix microarray, were selected from the Gene Expression Omnibus (GEO) database. Gene expression analyses were performed with the aim of identifying the expression patterns of $\mathrm{CIH}$-associated genes. Integrating the results of the present study with previous related studies allowed a more comprehensive interpretation of the molecular mechanism underlying $\mathrm{CIH}$ to be constructed at the gene expression level.

\section{Materials and methods}

Microarray data. The GSE13432 dataset was downloaded from the GEO database (http://www.ncbi.nlm.nih.gov/geo/). Sample information of the $12 \mathrm{C} 57 / \mathrm{B} 16$ mice that were maintained at 30 or $4^{\circ} \mathrm{C}$ for 1 or 5 weeks is listed in Table I. Data from the three mice in each group were used for gene expression analysis using the Mouse Genome 430 2.0 Array system (Affymetrix, Inc., Santa Clara, CA, USA). The robust multichip analysis algorithm was used to polish the microarray data prior to further analysis (21).

Differentially expressed gene (DEG) detection. Based on the Bayesian statistical model, DEGs were identified between the 4 and $30^{\circ} \mathrm{C}$ groups at the various timescales $\left(4^{\circ} \mathrm{C} 1\right.$ week $/ 30^{\circ} \mathrm{C}$ 1 week, $4^{\circ} \mathrm{C} 5$ weeks $/ 30^{\circ} \mathrm{C} 5$ weeks). Statistical t-tests with multiple test correction using the Benjamini and Hochberg procedure (22) were performed with the threshold of significantly expressed genes set at a false discovery rate (FDR) of 0.01. Up- or downregulation of DEGs was determined as fold change.

Gene Ontology (GO) and pathway analysis of DEGs. All cold-induced DEGs were mapped according to the GO 
Table I. Characteristics of the sample information.

\begin{tabular}{|c|c|c|c|}
\hline GEO identification & Sample description & Sample name & Raw file data \\
\hline GSM338983 & 1 week $30^{\circ} \mathrm{C}$ rep 1 & $\mathrm{C} 1-1$ & GSM338983.cel.gz \\
\hline GSM338984 & 1 week $30^{\circ} \mathrm{C}$ rep 2 & $\mathrm{C} 1-2$ & GSM338984.cel.gz \\
\hline GSM338985 & 1 week $30^{\circ} \mathrm{C}$ rep 3 & $\mathrm{C} 1-3$ & GSM338985.cel.gz \\
\hline GSM338986 & 1 week $4^{\circ} \mathrm{C}$ rep 1 & D1-1 & GSM338986.cel.gz \\
\hline GSM338987 & 1 week $4^{\circ} \mathrm{C}$ rep 2 & D1-2 & GSM338987.cel.gz \\
\hline GSM338988 & 1 week $4^{\circ} \mathrm{C}$ rep 3 & D1-3 & GSM338988.cel.gz \\
\hline GSM338989 & 5 weeks $30^{\circ} \mathrm{C}$ rep 1 & C5-1 & GSM338989.cel.gz \\
\hline GSM338990 & 5 weeks $30^{\circ} \mathrm{C}$ rep 2 & C5-2 & GSM338990.cel.gz \\
\hline GSM338991 & 5 weeks $30^{\circ} \mathrm{C}$ rep 3 & C5-3 & GSM338991.cel.gz \\
\hline GSM338992 & 5 weeks $4^{\circ} \mathrm{C}$ rep 1 & D5-1 & GSM338992.cel.gz \\
\hline GSM338993 & 5 weeks $4^{\circ} \mathrm{C}$ rep 2 & D5-2 & GSM338993.cel.gz \\
\hline GSM338994 & 5 weeks $4^{\circ} \mathrm{C}$ rep 3 & D5-3 & GSM338994.cel.gz \\
\hline
\end{tabular}

GEO, Gene Expression Omnibus.

(http://www.geneontology.org) and Kyoto Encyclopedia of Genes and Genomes pathway terms (http://www.genome.jp/ $\mathrm{kegg} /$ ). Multiple models for pathway enrichment evaluation were utilized $(23,24)$. Blood pressure-associated DEGs were defined by blood pressure-associated GO function terms, while hypertension-associated DEGs were selected from hypertension-associated pathways identified by known hypertension genes in the Online Mendelian Inheritance in Man (OMIM) database and the Mammalian Phenotype Ontology in the Mouse Genome Informatics (MGI) database (http://www. omim.org and http://www.informatics.jax.org/). Odds ratios and FDRs were calculated with a threshold FDR value of 0.05 to identify statistical significance of pathway enrichment. Kernel principal component analysis was used to evaluate the overall gene expression differences between samples. All these procedures were performed with $\mathrm{R}$ statistical software (v 2.14.1; http://www.r-project.org/), and Bioconductor limma packages (3.12.1) and libraries (25) (http://www.bioconductor. org/packages/devel/bioc/html/limma.html).

Protein-protein interaction (PPI) network analysis. Network inference was performed using Cytoscape (26) (v 2.8.3; http://www.cytoscape.org/). The interaction dataset between genes was downloaded from the Biomolecular Interaction Network Database (http://bind.ca) and the MIPS Mammalian Protein-Protein Interaction Database (MPPI; http://mips. helmholtz-muenchen.de/proj/ppi/). The network was analyzed for cold-induced DEGs associated with blood pressure regulation and hypertension in two case/control groups $\left(4^{\circ} \mathrm{C}\right.$ for 1 week vs. $30^{\circ} \mathrm{C}$ for 1 week and $4^{\circ} \mathrm{C}$ for 5 weeks vs. $30^{\circ} \mathrm{C}$ for 5 weeks).

\section{Results}

Cold-induced DEG profiling. The downloaded GSE13432 dataset contained the gene expression data of four groups of mice (three replicates in each) exposed to four conditions: $4^{\circ} \mathrm{C}$ for 1 and 5 weeks and their respective controls at $30^{\circ} \mathrm{C}$ for 1 and 5 weeks (27). In order to demonstrate the gene expression level changes that resulted from cold exposure, analysis of DEGs was performed between the cold exposure mice and the control groups for the two timescales. Multiple testing with FDR control was conducted to improve the accuracy of the results.

In total, 5,183 DEGs were identified in the $4^{\circ} \mathrm{C} 1$ week vs. $30^{\circ} \mathrm{C} 1$ week group, while 5,580 DEGs were identified in the $4^{\circ} \mathrm{C} 5$ week vs. $30^{\circ} \mathrm{C} 5$ week group (FDR, <0.01). Among these DEGs, 2,800 genes maintained increased or decreased expression levels at week 1 and 5, while $>2,000$ genes were detected only at week 1 or 5 , as shown in Fig. 1.

With regard to the most significant DEGs, the expression levels of uncoupling protein $1(U C P 1)$, a mitochondrial proton carrier, and a series of other fatty acid metabolic genes, including ELOVL3, FABP3 and $C P T 1 B$, were markedly elevated in the two cold exposure groups. In addition, energy metabolism genes associated with oxidative phosphorylation, the citrate cycle and mitochondrial function were also shown to be upregulated, including the ubiquinol-cytochrome $c$ reductase $(U Q C R)$ and cytochrome $c$ oxidase $(C O X)$ gene families. Peroxisome genes were also activated in the two groups. Notably, following cold exposure, the number of downregulated genes was nearly double the number of upregulated genes.

Cold exposure regulates the expression levels of blood pressure-associated genes. A total of 52 DEGs associated with blood pressure regulation were selected according to the GO terms and descriptions. Expression patterns were constructed with clustering analysis and are shown in Fig. 2. In total, 18 DEGs were observed that were differentially expressed after 1 and 5 weeks of exposure. In addition, six genes were identified to have a larger difference at the expression level with long term exposure, including superoxide dismutase 2 (SOD2), glucose-6-phosphate dehydrogenase X-linked (G6pdx), WNK lysine deficient protein kinase $1(W n k l)$, peroxisome proliferator activated receptor $\alpha$ (Ppara), cytochrome b-245, 


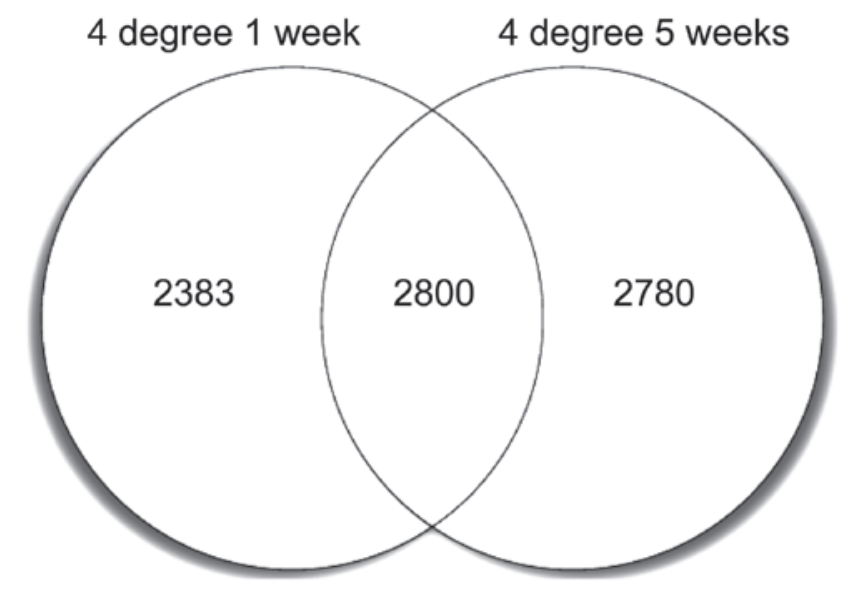

Figure 1. Venn plot showing the identified DEGs in the two cold-exposure groups. A total of 5,183 DEGs were identified in the $4^{\circ} \mathrm{C} 1$ week vs. $30^{\circ} \mathrm{C} 1$ week group, while $5,580 \mathrm{DEGs}$ were identified in the $4^{\circ} \mathrm{C} 5$ week vs. $30^{\circ} \mathrm{C} 5$ week group (FDR, <0.01). Among the DEGs, 2,800 genes maintained increased or decreased expression levels after week 1 and 5, while $>2,000$ genes were detected only at week 1 or 5. DEGs, differentially expressed genes; FDR, false discovery rate.
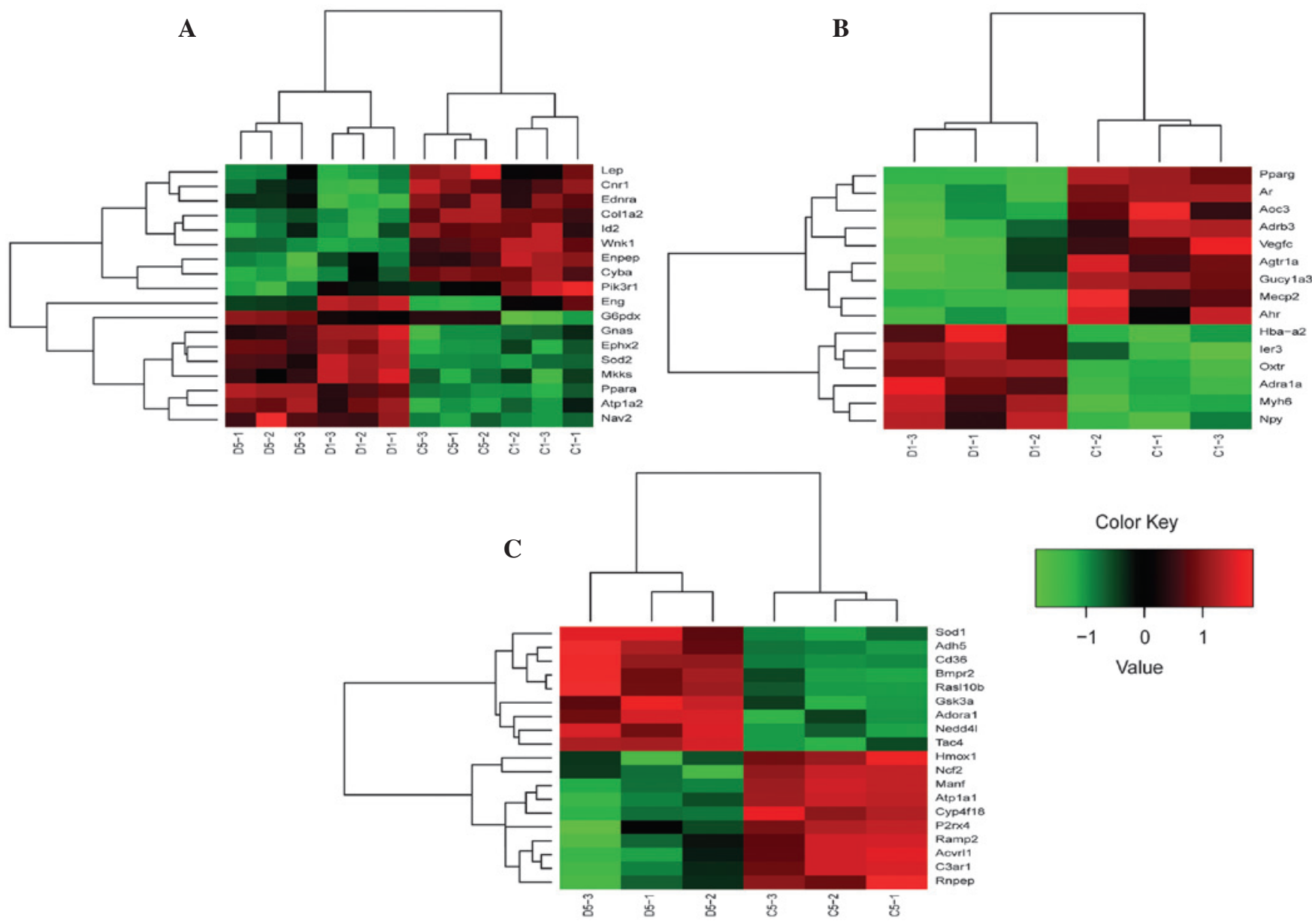

Figure 2. Heatmaps demonstrating the expression levels of blood pressure-associated genes in (A) all mice and the (B) $4^{\circ} \mathrm{C} 1$ week and (C) $4^{\circ} \mathrm{C} 5$ week groups Information for each sample corresponding to Table I is shown on the X-axis.

$\alpha$ polypeptide $(C y b a)$ and ATPase, $\mathrm{Na}^{+} / \mathrm{K}^{+}$transporting, $\alpha 2$ polypeptide (Atpla2). Furthermore, there were a number of 1 week specific DEGs that exhibited a transient expression pattern following 1 week exposure, but returned to the initial values by week 5 , including angiotensin II receptor type 1a (Agtrla) and adrenergic receptor $\alpha$ 1a (Adrala). There were also specific genes considered to be slow-response genes that were only observed after 5 weeks of cold exposure.

Hypertension-associated pathway analysis. In order to exclude unassociated pathways that were caused by cold acclimation, the OMIM and MGI databases were searched and 
Table II. KEGG enriched pathways of hypertension-associated genes in the OMIM and MGI databases.

\begin{tabular}{|c|c|c|c|c|}
\hline Pathways & Odds ratio & P-value & FDR & Subclass \\
\hline \multicolumn{5}{|l|}{$4^{\circ} \mathrm{C} 1$ week group } \\
\hline Huntington's disease & 3.087 & $7.465 \mathrm{E}-13$ & $4.852 \mathrm{E}-11$ & Neurodegenerative disease \\
\hline Alzheimer's disease & 2.924 & $1.590 \mathrm{E}-11$ & $8.270 \mathrm{E}-10$ & Neurodegenerative disease \\
\hline Peroxisome & 2.824 & 3.937E-06 & $1.462 \mathrm{E}-04$ & Transport and catabolism \\
\hline Fatty acid metabolism & 3.635 & $2.425 \mathrm{E}-05$ & $6.736 \mathrm{E}-04$ & Lipid metabolism \\
\hline \multicolumn{5}{|l|}{$4^{\circ} \mathrm{C} 5$ week group } \\
\hline Huntington's disease & 2.631 & $6.559 \mathrm{E}-10$ & $4.263 \mathrm{E}-08$ & Neurodegenerative disease \\
\hline Alzheimer's disease & 2.433 & $1.903 \mathrm{E}-08$ & $8.246 \mathrm{E}-07$ & Neurodegenerative disease \\
\hline Phagosome & 2.364 & 7.954E-08 & 2.954E-06 & Transport and catabolism \\
\hline Epstein-Barr virus infection & 1.988 & $1.306 \mathrm{E}-06$ & $3.525 \mathrm{E}-05$ & Infectious disease \\
\hline Toxoplasmosis & 2.483 & $1.746 \mathrm{E}-06$ & $4.127 \mathrm{E}-05$ & Infectious disease \\
\hline Chemokine signaling & 1.976 & 4.920E-06 & $9.841 \mathrm{E}-05$ & Immune system \\
\hline Osteoclast differentiation & 1.989 & $1.207 \mathrm{E}-04$ & $1.847 \mathrm{E}-03$ & Development \\
\hline B cell receptor signaling & 2.330 & $1.886 \mathrm{E}-04$ & $2.725 \mathrm{E}-03$ & Immune system \\
\hline Tuberculosis & 1.744 & $2.129 \mathrm{E}-04$ & $2.913 \mathrm{E}-03$ & Infectious disease \\
\hline Hepatitis B & 1.807 & $3.237 \mathrm{E}-04$ & $4.208 \mathrm{E}-03$ & Infectious disease \\
\hline Viral carcinogenesis & 1.618 & 4.905E-04 & $5.545 \mathrm{E}-03$ & Cancer \\
\hline Fc $\gamma$ R-mediated phagocytosis & 2.038 & 7.372E-04 & 7.986E-03 & Immune system \\
\hline Leishmaniasis & 2.108 & $1.980 \mathrm{E}-03$ & $1.716 \mathrm{E}-02$ & Infectious disease \\
\hline Pertussis & 2.013 & $2.506 \mathrm{E}-03$ & $1.975 \mathrm{E}-02$ & Infectious disease \\
\hline Acute myeloid leukemia & 2.112 & $3.787 \mathrm{E}-03$ & $2.825 \mathrm{E}-02$ & Cancer \\
\hline Hepatitis C & 1.605 & $5.119 \mathrm{E}-03$ & $3.597 \mathrm{E}-02$ & Infectious disease \\
\hline Peroxisome & 1.825 & $5.296 \mathrm{E}-03$ & $3.624 \mathrm{E}-02$ & Transport and catabolism \\
\hline Estrogen signaling & 1.723 & $5.638 \mathrm{E}-03$ & $3.758 \mathrm{E}-02$ & Endocrine system \\
\hline Fatty acid metabolism & 2.168 & $8.170 \mathrm{E}-03$ & $4.968 \mathrm{E}-02$ & Lipid metabolism \\
\hline $\mathrm{T}$ cell receptor signaling & 1.623 & $8.245 \mathrm{E}-03$ & $4.968 \mathrm{E}-02$ & Immune system \\
\hline Leukocyte transendothelial migration & 1.597 & 8.364E-03 & 4.968E-02 & Immune system \\
\hline
\end{tabular}

KEGG, Kyoto Encyclopedia of Genes and Genomes ; OMIM, Online Mendelian Inheritance in Man; MGI, Mouse Genome Informatics; FDR, false discovery rate.

51 genes were identified as known hypertension-associated genes. In order to identify how these genes were affected by cold exposure, enrichment analysis was performed in the associated pathways. Nervous system-associated pathways, including Huntington's and Alzheimer's diseases, were found to be significantly enriched (odds ratio, $>2$; FDR, $<10^{-6}$ ) in the two cold exposure groups. In addition, immune system pathways were specifically enriched in the 5 week exposure group, including the chemokine signaling pathway, B cell receptor signaling pathway and $\mathrm{Fc} \gamma \mathrm{R}$-mediated phagocytosis (Table II).

PPI network. According to the MPPI database, numerous genes $\left(4^{\circ} \mathrm{C} 1\right.$ week group, $327 ; 4^{\circ} \mathrm{C} 5$ week group, 515) were identified for construction of the network. It was possible to organize the majority of the genes into a single network. Proteins associated with signal transduction were observed in the PPI network of the $4^{\circ} \mathrm{C} 1$ week group, including certain proteins associated with the hypoxia-inducible factor (HIF-1) and mitogen-activated protein kinase (MAPK) signaling pathways. A number of additional proteins associated with the immune system were identified in the $4^{\circ} \mathrm{C} 5$-week mice, including mammalian target of rapamycin (mTOR) and $\mathrm{B}$ and $\mathrm{T}$ cell receptor signaling pathways.

\section{Discussion}

Cold exposure is hypothesized to be an important factor contributing to hypertension. However, the pathogenic mechanism of $\mathrm{CIH}$ is not fully understood. Although hypertension is defined as a condition of high blood pressure, the disorder is complex with numerous phenotypes and a number of causative factors, including genetics and environmental factors (8). Thus, mice models that were only exposed to cold were selected for the present study. The results of the present study indicate that a myriad of genes were expressed differentially when adapting to cold acclimation. Genes associated with thermogenesis (UCPI) and energy metabolism (UQCR and COX families) were activated as more heat and energy were required to maintain temperature homeostasis (9). Thus, the compensatory increase in the metabolic rate causes tissue hypoxia, as previously demonstrated (27). The expression of endothelial 
PAS domain-containing protein 1 (Epasl) was upregulated, indicating that the HIF signaling pathway was activated. HIF-associated genes also exhibited regulated expression levels and were observed in the PPI networks. Genes associated with oxidative stress, including SOD2 and epoxide hydrolase 2 (EPHX2), were also shown to be significantly upregulated with DEG and pathway analyses of blood pressure-associated genes. In addition, hypertension-associated gene analysis revealed that pathways associated with oxidative stress were markedly enriched in the initial exposure group ( $4^{\circ} \mathrm{C}$ for 1 week). Huntington's and Alzheimer's disease pathways are associated with mitochondrial dysfunction and the peroxisome pathway plays a crucial role in free radical detoxification. Furthermore, a number of additional immune system pathways were enriched in the chronic exposure group $\left(4^{\circ} \mathrm{C}\right.$ for 5 week), which may further induce inflammatory reactions and increase oxidative stress (28-30). Therefore, the results of the present study indicate that an imbalance in reactive oxygen species and superoxide caused by hypoxia and oxidative stress may contribute to the initiation of hypertension, while chronic cold exposure may accumulate the effect of oxidative stress in the process of hypertension.

\section{References}

1. Aubinière-Robb L, Jeemon $\mathrm{P}$, Hastie CE, et al: Blood pressure response to patterns of weather fluctuations and effect on mortality. Hypertension 62: 190-196, 2013.

2. Fu S, Cao Y and Li Y: Epidemiological study of hypertension in Heilongjiang province. Zhonghua Nei Ke Za Zhi 41: 114-116, 2002 (In Chinese).

3. Gyllerup S, Lanke J, Lindholm LH and Scherstén B: High coronary mortality in cold regions of Sweden. J Intern Med 230: 479-485, 1991.

4. Jakovljević D, Salomaa V, Sivenius J, et al: Seasonal variation in the occurrence of stroke in a Finnish adult population. The FINMONICA Stroke Register. Finnish Monitoring Trends and Determinants in Cardiovascular Disease. Stroke 27: 1774-1779, 1996.

5. Seretakis D, Lagiou P, Lipworth L, Signorello LB, Rothman KJ and Trichopoulos D: Changing seasonality of mortality from coronary heart disease. JAMA 278: 1012-1014, 1997.

6. Sun Z: Cardiovascular responses to cold exposure. Front Biosci (Elite Ed) 2: 495-503, 2010

7. Kim JY, Jung KY, Hong YS, Kim JI, Jang TW and Kim JM: The relationship between cold exposure and hypertension. J Occup Health 45: 300-306, 2003.

8. Brook RD, Weder AB and Rajagopalan S: 'Environmental hypertensionology' the effects of environmental factors on blood pressure in clinical practice and research. J Clin Hypertens (Greenwich) 13: 836-842, 2011.

9. Blankfield RP: The thermoregulatory-vascular remodeling hypothesis: an explanation for essential hypertension. Med Hypotheses 66: 1174-1178, 2006.

10. Sun Z, Cade R and Morales C: Role of central angiotensin II receptors in cold-induced hypertension. Am J Hypertens 15: 85-92, 2002.
11. Patel D, Böhlke M, Phattanarudee S, Kabadi S, Maher TJ and Ally A: Cardiovascular responses and neurotransmitter changes during blockade of angiotensin II receptors within the ventrolateral medulla. Neurosci Res 60: 340-348, 2008.

12. Sun Z, Fregly MJ and Cade JR: Effect of renal denervation on elevation of blood pressure in cold-exposed rats. Can J Physiol Pharmacol 73: 72-78, 1995.

13. Wang X, Sun Z and Cade R: Prolonged attenuation of cold-induced hypertension by adenoviral delivery of renin antisense. Kidney Int 68: 680-687, 2005.

14. Sun Z, Wang X, Wood CE and Cade JR: Genetic AT1A receptor deficiency attenuates cold-induced hypertension. Am J Physiol Regul Integr Comp Physiol 288: R433-R439, 2005.

15. Chen GF and Sun Z: Effects of chronic cold exposure on the endothelin system. J Appl Physiol (1985) 100: 1719-1726, 2006.

16. Grossman E: Does increased oxidative stress cause hypertension? Diabetes Care 31 (Suppl 2): S185-S189, 2008.

17. Nishiyama A, Yao L, Nagai Y, et al: Possible contributions of reactive oxygen species and mitogen-activated protein kinase to renal injury in aldosterone/salt-induced hypertensive rats. Hypertension 43: 841-848, 2004.

18. Park JB, Touyz RM, Chen X and Schiffrin EL: Chronic treatment with a superoxide dismutase mimetic prevents vascular remodeling and progression of hypertension in salt-loaded stroke-prone spontaneously hypertensive rats. Am J Hypertens 15: 78-84, 2002.

19. Rodriguez-Iturbe B, Zhan CD, Quiroz Y, Sindhu RK and Vaziri ND: Antioxidant-rich diet relieves hypertension and reduces renal immune infiltration in spontaneously hypertensive rats. Hypertension 41: 341-346, 2003.

20. Tanito M, Nakamura H, Kwon YW, et al: Enhanced oxidative stress and impaired thioredoxin expression in spontaneously hypertensive rats. Antioxid Redox Signal 6: 89-97, 2004.

21. Giorgi FM, Bolger AM, Lohse M and Usadel B: Algorithm-driven artifacts in median polish summarization of microarray data. BMC Bioinformatics 11: 553, 2010.

22. Benjamini Y and Hochberg Y: Controlling the false discovery rate: a practical and powerful approach to multiple testing. Journal of the Royal Statistical Society, Series B 57: 289-300, 1995.

23. Kirik U, Cifani P, Albrekt AS, Lindstedt M, Heyden A and Levander F: Multimodel pathway enrichment methods for functional evaluation of expression regulation. J Proteome Res 11: 2955-2967, 2012

24. Shen K and Tseng GC: Meta-analysis for pathway enrichment analysis when combining multiple genomic studies. Bioinformatics 26: 1316-1323, 2010.

25. Smyth GK, Michaud J and Scott HS: Use of within-array replicate spots for assessing differential expression in microarray experiments. Bioinformatics 21: 2067-2075, 2005.

26. Saito R, Smoot ME, Ono K, et al: A travel guide to Cytoscape plugins. Nat Methods 9: 1069-1076, 2012.

27. Xue Y, Petrovic N, Cao R, et al: Hypoxia-independent angiogenesis in adipose tissues during cold acclimation. Cell Metab 9: 99-109, 2009

28. Pruijm M, Hofmann L, Vogt B, et al: Renal tissue oxygenation in essential hypertension and chronic kidney disease. Int J Hypertens 2013: 696598, 2013.

29. Nangaku M and Eckardt KU: Hypoxia and the HIF system in kidney disease. J Mol Med (Berl) 85: 1325-1330, 2007.

30. Prchal JT: Delivery on demand - a new era of gene therapy? N Engl J Med 348: 1282-1283, 2003. 